\title{
Merger of Glaxo Wellcome and SmithKline Beecham creates pharmaceutical giant
}

\section{Munich}

The merger of the British pharmaceutical companies Glaxo Wellcome and SmithKline Beecham, which comes into effect this summer, creates a giant which could rank number one in the world in terms of spending on research and development $(\mathrm{R} \& \mathrm{D})$ ). It will boast a portfolio of 30 new drugs and 19 vaccines in clinical trial.

Glaxo Wellcome is currently the fifthlargest pharmaceutical company in the world in terms of turnover and SmithKline Beecham is ranked twelfth. The new company will have a stock-market value of $\mathfrak{E} 110$ billion (US $\$ 180$ billion).

It displaces Aventis from the top position, a company created just a few weeks ago by the merger of Rhône-Poulenc and Hoechst. Meanwhile, the merger between Pfizer and Warner-Lambert, if it materializes, would create the second-largest company in the sector.

Savings made by merging the research sections of Glaxo Wellcome and SmithKline Beecham - estimated at $\$ 415$ million - will be reinvested in research, say the companies.

The new company plans to invest $\$ 4$ bil- lion a year in research. Its nearest rival would be Pfizer Warner Lambert, whose compo-

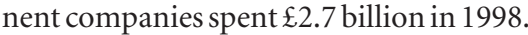

Glaxo SmithKline will employ over 15,000 research staff. None of its research departments will be closed and there is no threat of significant redundancies amongst scientists, according to a press release. The companies also promise to maintain their scientific campuses at Research Triangle Park, North Carolina, and Philadelphia.

The merger will combine the power of Glaxo Wellcome's strength in combinatorial chemistry and SmithKline Beecham's strength in genomics and cell and molecular biology. Glaxo Wellcome stands to have its product portfolio rejuvenated through SmithKline Beecham's genomic assets.

The strategies of the companies, stressing genome research, are similar and their therapeutic target areas are complementary: in neurology, for example, Glaxo Wellcome is active in anti-migraine drugs and SmithKline Beecham in anti-depressants.

SmithKline Beecham was the first major pharmaceutical company to invest in genomics, with its 1993 agreement with Human Genome Sciences, the commercial arm of the Institute for Genomics Research, where Craig Venter first made sequencing fashionable. As a result of its genomics activities, SmithKline Beecham Garnier: to head now investigates Glaxo SmithKline. between 150 and 200

new protein targets each year, compared with six to eight before 1993.

Glaxo Wellcome also has functionalgenomics programmes and invests heavily in pharmacogenetics, a genomics-based activity that allows patients likely to benefit from a drug, or to suffer adverse side effects, to be identified before therapy is selected.

Given the long lead time for getting any new drug onto the market, analysts say it will be at least five years before it is clear whether the merged company will get a return on its investment in genomics.

Alison Abbott

\section{NASA ponders termination of gamma-ray observatory}

\section{Washington}

The US space agency NASA may retire the Compton Gamma Ray Observatory satellite as early as this March, unless it can ensure that the spacecraft will not crash back to Earth following last month's failure of an onboard gyroscope.

Launched in 1991, the $\$ 600$ million observatory has already outlived its planned lifetime, but was expected to stay in orbit for another eight to ten years.

Although the satellite can operate normally with its two remaining gyroscopes, it could not be pointed if another one fails. NASA has always intended to steer the spacecraft to a fiery re-entry over the ocean at the end of its useful life. An uncontrolled re-entry risks large chunks of

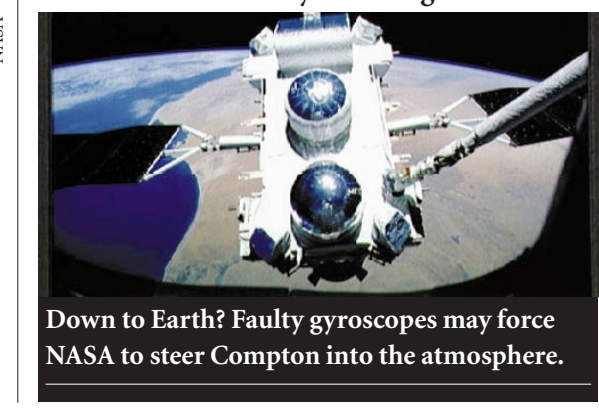

the 17-tonne observatory crashing into populated areas.

Engineers at the NASA Goddard Space Flight Center will know in mid-February whether the spacecraft can be controlled with one or no gyros. If not, other options include sending astronauts on the space shuttle to carry out repairs, boosting the observatory to a higher orbit or 'de-

orbiting' the spacecraft as soon as possible, while it can still be controlled.

Compton has been a "very productive mission" and is still valuable, according to Kevin Hurley of the University of California at Berkeley, who chairs the observatory's scientific users' committee.

No other high-energy satellite can cover the entire sky; but the Compton mission has passed its peak of scientific productivity, and one gamma-ray telescope, EGRET, is barely operational. NASA's review of the project in 1998 called for it to continue at a reduced funding level, but said that: "Except for solar observations, the potential for new discoveries is diminishing."

There are several gamma-ray satellites in the works. The European Space Agency's International Gamma-Ray Astrophysics Laboratory, a collaboration with the United
States and Russia, is due to launch next year NASA's SWIFT mission to hunt for gammaray bursts will begin in 2003. And HETE-II, a low-cost spacecraft run for NASA by the Massachusetts Institute of Technology, is due to reach orbit this spring.

HETE-II was supposed to be launched from Kwajalein Atoll in the Pacific Ocean on 28 January. But, following last month's failure of the Mars Polar Lander, NASA headquarters last week ordered HETE-II removed from its Pegasus launcher to undergo a final round of testing.

That sense of caution - and the desire to avoid embarrassment — will influence NASA's decision. If Goddard engineers fail to convince NASA headquarters that the spacecraft can be controlled without gyros, an early de-orbit is likely. A space-shuttle rescue would be costly, and would take a long time to plan. Boosting the orbit would defer the plummet to Earth for a century or more.

Some defenders of Compton point out that it will not fall to Earth for at least six years. Another idea discussed - only half seriously, says Hurley — is letting the US defense department shoot down the satellite for target practice.

Tony Reichhardt 